\title{
Options introduction and volatility in the EU ETS ${ }^{1}$
}

\author{
Julien Chevallier ${ }^{2}$ \\ Imperial College London (Grantham Institute for Climate Change) and University of \\ Paris 10 (EconomiX-CNRS)
}

Yannick Le Pen ${ }^{3}$

University of Nantes (LEMNA)

\author{
Benoît Sévi ${ }^{4}$ \\ University of Angers (GRANEM), LEMNA and CEREBEM (Bordeaux Management \\ School)
}

First Version: January 2009

This Version: July 2009

\begin{abstract}
To improve risk management in the European Union Emissions Trading Scheme (EU ETS), the European Climate Exchange (ECX) has introduced option instruments in October 2006 after regulatory authorization. The central question we address is: can we identify a potential destabilizing effect of the introduction of options on the underlying market (EU ETS futures)? Indeed, the literature on commodities futures suggest that the introduction of derivatives may either decrease (due to more market depth) or increase (due to more speculation) volatility. As the identification of these effects ultimately remains an empirical question, we use daily data from April 2005 to April 2008 to document volatility behavior in the EU ETS. By instrumenting various GARCH models, endogenous break tests, and rolling window estimations, our results overall suggest that the introduction of the option market had no effect on the volatility in the EU ETS. These finding are robust to other likely influences linked to energy and commodity markets.
\end{abstract}

JEL Classification: Q48; Q57; Q58.

Keywords: EU ETS; Option prices; Volatility; GARCH; Rolling Estimation; Endogenous Structural Break Detection.

\footnotetext{
${ }^{1}$ Helpful comments were received from seminar participants at the 32nd IAEE conference (San Francisco, 2009) and the 17th EAERE annual meeting (Amsterdam, 2009). We also warmly thank Derek Bunn for his insightful comments on earlier drafts of this paper, and Stewart Mayhew for his advices on the issue of derivatives introduction. All remaining errors are ours.

${ }^{2}$ Address for correspondence: Imperial College of Science, Technology and Medicine, South Kensington Campus, SW7 2AZ London, UK. Email address: j.chevallier@imperial.ac.uk

${ }^{3}$ Address for correspondence: Institut d'Économie et de Management de Nantes - IAE, Université de Nantes, Chemin de la Censive du Tertre, BP 52231, 44322 Nantes cedex 3. Email address: yannick.le-pen@univ-nantes.fr

${ }^{4}$ Address for correspondence: Faculté de Droit, Économie et Gestion, Université d'Angers, 13 allée François Mitterrand, BP 13633, 49036 Angers cedex 01. Email address: benoit.sevi@gmail.com
} 


\section{Introduction}

To what extent does the introduction of option prices tend to destabilize tradable permits markets? Indeed, allowing for option trading in a regulated market may have some consequences on volatility in the underlying market. On the one hand, most of the empirical evidence for equities, bonds and commodities suggests that options do not increase volatility, but rather increase the liquidity and the informational efficiency of the underlying market. On the other hand, the introduction of options may affect the volatility of the underlying market, since they affect producers' decisions through intertemporal arbitrage (Weaver and Banerjee (1990)). Options may also guide producers' decisions based on a mix of true information and speculators' noise signals (Back (1993)).

Previous empirical literature provides mixed conclusions concerning the introduction of options. In an exhaustive survey on this topic, Mayhew (2000) shows ambiguous effects of the introduction of derivatives on the volatility of the underlying asset, i.e. it may be either positive or negative depending on the market under consideration (equities, bonds, or commodities). Fleming and Ostdiek (1999) have contributed to the analysis of the introduction of derivatives instruments on the underlying crude oil market and derived products. Thus, detecting whether the introduction of options has increased or decreased volatility in the European Union Emissions Trading Scheme (EU ETS) remains an empirical issue worth of investigation.

The EU ETS is a compliance market, which means that each installation of the approximately 10,600 covered installations needs to surrender each year a number of allowances, fixed by each Member State in its National Allocation Plan (NAP), equal to its verified emissions (Ellerman and Buchner (2008), Alberola et al. (2009)). To comply with their emissions target, installations may exchange quotas either over-the-counter, or through brokers and market places. ${ }^{5}$ Bluenext ${ }^{6}$ is the market place dedicated to $\mathrm{CO}_{2}$ allowances based in Paris. It has been created on June 24, 2005 and has become the most liquid platform for spot trading. ${ }^{7}$ The European Climate Exchange (ECX) is the market place based in London. It has been created on April 22, 2005 and is the most liquid platform for futures and option trading. ${ }^{8}$

Following the rapid development of spot and futures trading on these exchanges ${ }^{9}$, more sophisticated carbon products have been progressively introduced, thereby offering to market participants a greater flexibility in the management of their compliance requirements. Option prices have been introduced by ECX on October 13, 2006. ${ }^{10}$ The introduction of carbon option prices naturally raises the question of their utility for market agents. There are mainly two uses of options: (i) for speculation purpose in order to make a profit from trading, and (ii) for hedging purpose, in order to reduce or eliminate

\footnotetext{
${ }^{5}$ To guarantee compliance, any reported violation may be associated with a high penalty (Stranlund et al. (2005)). The existence of a hedging (option) instrument may facilitate compliance, and as such be viewed as a complement of enforcing policies.

${ }^{6}$ Formerly called Powernext Carbon.

$772 \%$ of the volume of spot contracts are traded on Bluenext (Reuters).

$896 \%$ of the volume of futures contracts are traded on ECX (Reuters).

${ }^{9}$ Other exchanges are worth mentioning: (i) NordPool, which represents the market place common to Denmark, Finland, Sweden, Norway, and is based in Oslo; (ii) the European Energy Exchange (EEX), based in Leipzig, trading spot and derivatives products for emissions allowances rights; and (iii) the New York Mercantile Exchange (NYMEX), based in the U.S., which is also trading European futures and options emissions rights. The price of products exchanged on these market places are strongly correlated, which is also a feature of stock markets.

${ }^{10}$ Note option prices have also been introduced by EEX on March 5, 2008. However, we do not have enough historical data at hand for this product and liquidity was known to be very low. So, we decide to focus on ECX option prices only. The study of discrepancies between ECX and EEX option prices is left for further research.
} 
the risk in a position. The second use obviously allows industrials to lower the economic, political and financial uncertainties attached to market developments in the EU ETS. Böhringer et al. (2008) emphasize that overlapping regulatory instruments should be avoided to achieve efficiency in global environmental policy. The main "environmental policy"-related risk for industrials would then consist in permits price changes, which could be strongly reduced by using hedging instruments such as options.

Empirical studies of the EU ETS option market remain scarce. Uhrig-Homburg and Wagner (2007) describe extensively derivative instruments in the EU carbon market based on qualitative surveys. Chesney and Taschini (2008) provide an application of $\mathrm{CO}_{2}$ price dynamics modeling to option pricing. Chevallier et al. (2009) provide a case-study of investors' changes in risk aversion around the 2006 compliance event using both futures and option prices. To our best knowledge, no prior study has investigated the impact of the options introduction in the EU ETS on the characteristics of the underlying carbon price in terms of volatility.

When introducing option trading in October 2006, the ECX may have indirectly increased the volatility of the underlying futures market. Indeed, the higher the leverage effect associated with option trading, the higher speculation about fuel substitution develops, which translates into rising volatility. This effect has been observed in some other markets and is generally viewed as a negative externality by the regulator. More specifically, we examine the following central questions: what is the impact of the option market on the carbon price in terms of volatility? Is the introduction of the option market the only cause behind volatility changes? The latter question leads us to consider other factors such as institutional decisions, energy and global commodity markets to which volatility changes could be attributed as well.

Our empirical study departs from previous literature on several aspects. First, we develop a GARCH model with a dummy variable to study the impact of the introduction of the option market (Antoniou and Foster (1992), Antoniou and Holmes (1995), Gulen and Mayhew (2000)). Then, we proceed with an endogenous structural break test (Inclán and Tiao (1994), Sansó, Aragó and Carrion (2004)) to detect more precisely the influence of options introduction. To the best of our knowledge, this kind of test has not been used for such a purpose yet. After taking into account the volatilities of several energy- and commodity-related variables, we do not observe any impact of the introduction of the option market on the volatility of the carbon futures prices. These results therefore suggest that the observed changes in the unconditional component of volatility for EU ETS futures returns and the introduction of options are not linked.

This econometric analysis is finally taken one step further by using rolling estimations with a window of 200 observations. Results reveal the influence of the 2005 and 2006 compliance events on the volatility of $\mathrm{CO}_{2}$ returns, but also clearly feature a long-lasting influence of options introduction (during several months). We are thus able to identify in a dynamic framework the impact of the introduction of the option market on volatility in the EU ETS (and not only as a "one-off" event as in previous literature). Overall, our article brings a better understanding of the role played by the option market on the volatility of the carbon price in the EU ETS.

The remainder of the paper is organized as follows. Section 2 presents the carbon futures and option markets. Section 3 summarizes the data used. Section 4 details the econometric methodology, along 
with estimation results. Section 5 concludes.

\section{Overview of the futures and option markets in the EU ETS}

In what follows, we detail key design issues, the volume of transactions, as well as the introduction of futures and option prices in the EU ETS.

\subsection{Key design issues}

The EU ETS has been created by the Directive 2003/87/CE. Across its 27 Member States, it covers large plants from $\mathrm{CO}_{2}$-intensive emitting industrial sectors with a rated thermal input exceeding 20 MWh. One allowance exchanged on the EU ETS corresponds to one ton of $\mathrm{CO}_{2}$ released in the atmosphere, and is called a European Union Allowance (EUA). 2.2 billion allowances per year have been distributed during Phase I (2005-2007). 2.08 billion allowances per year will be distributed during Phase II (2008-2012). With a value of around $€ 20$ per allowance, the launch of the EU ETS thus corresponds to a net creation of wealth of around $€ 40$ billion per year. On January 2008, the European Commission has extended the scope of the EU trading system to other sectors such as aviation and petro-chemicals by 2013, and confirmed its functioning Phase III until 2020.

\subsection{Transactions}

During Phase I (2005-2007), the total volume of allowances exchanged in the EU ETS has been steadily increasing. The number of transactions has been multiplied by a factor four between 2005 and 2006, going from 262 to 809 million tons. This increasing liquidity of the market has been confirmed in 2007, where the volume of transactions recorded equals 1.5 billion tons. This peak of transactions may be explained by the growth of the number of contracts valid during Phase II, with delivery dates going from December 2008 to December 2012, which amount for $4 \%$ of total exchanges in 2005, and $85 \%$ in 2007. These transactions reached $€ 5.97$ billion in 2005 , $€ 15.2$ billion in 2006 , and $€ 24.1$ billion in 2007, thereby confirming the fact that the EU ETS represents the largest emissions trading scheme to date in terms of transactions.

In 2008, the carbon market was worth between €89-94 billion, up more than $80 \%$ year-on-year (Reuters). The launch of secondary certified emission reduction (CER $)^{11}$ contracts on ECX certainly fostered this growth rate of transactions.

\section{$2.3 \quad$ Futures market}

We choose to model the behavior of the ECX futures prices for the carbon time-series in this article. One reason is that, due to the banking restrictions implemented between 2007 and 2008 (Alberola

\footnotetext{
${ }^{11}$ According to the article 12 of the Kyoto Protocol, Credit Development Mechanisms (CDM) projects consist in achieving GHG emissions reduction in non-Annex B countries. After validation, the UNFCCC delivers credits called Certified Emissions Reductions (CERs) that may be used by Annex B countries for use towards their compliance position. CERs are fungible with EU ETS allowances with a maximum limit of around $13.4 \%$ on average.
} 
and Chevallier, 2009), spot prices show a non-reliable behavior during Phase ${ }^{12}$. We detail below the main characteristics of ECX futures.

\subsubsection{Contract specifications}

The futures contract is a deliverable contract where each member with a position open at cessation of trading for a contract month is obliged to make or take delivery of emission allowances to or from national registries. The unit of trading is one lot of 1,000 emission allowances. Each emission allowance represents an entitlement to emit one ton of carbon dioxide equivalent gas. Market participants may purchase consecutive contract months to March 2008, and then December contract months from December 2008 to December 2012. ${ }^{13}$ Delivery occurs by mid-month of the expiration contract date. Trading occurs from 07.00AM to 05.00PM GMT.

\subsubsection{Volume analysis}

The trading of ECX futures started on April 22, 2005 with varying delivery dates going from December 2005 to December 2012. Futures contracts with vintages December 2013 and 2014 were introduced on April 8, 2008. For the December 2009 futures contract, futures trade at $€ 13.32 /$ ton of $\mathrm{CO}_{2}$ as of January 15, 2009, and have reached a maximum price of $€ 32.90 /$ ton of $\mathrm{CO}_{2}$ in 2008. ${ }^{14}$ From April 2005 to January 2009, the total volume of ECX futures exchanged for all vintages is equal to 40.67 billion.

\subsection{Option market}

We describe below the main characteristics of ECX option prices.

\subsubsection{Contract specifications}

ECX option trading started on October 13, 2006. The underlying security for option trading is the ECX futures contract of corresponding maturity. Options have been introduced on ECX as Europeanstyle options, i.e. option prices convey the right, but not the obligation to buy (call) or sell (put) the underlying asset at a specified strike price and expiration date. ${ }^{15}$ Similarly, the contract size is 1,000 emissions allowances. On January 15, 2009 for the underlying futures price of $13.28 € /$ ton of $\mathrm{CO}_{2}$, calls and puts finance rates were equal to, respectively, $€ 2.64$ and $€ 2.31$ with 328 days remaining to the option expiration. The strike prices available range from 6 to $20 € /$ ton of $\mathrm{CO}_{2}$ with unitary increases. Expiration dates for ECX option prices are summarized in table 1.

\footnotetext{
${ }^{12}$ Besides, in the EU ETS, allowances need to be surrendered only on a yearly basis during the compliance event by mid-May, which makes the distinction between spot and forward prices less relevant than on other commodity markets such as the crude oil or the electricity market where storage costs are important. Note by contrast that storage costs are zero for $\mathrm{CO}_{2}$ allowances.

${ }^{13}$ Note spreads between two futures contracts may also be traded.

${ }^{14}$ In the longer term, analysts forecast EUA prices of $€ 20-25 /$ ton of $\mathrm{CO}_{2}$ over Phase II and $€ 25-30 /$ ton of $\mathrm{CO}_{2}$ over Phase III (Reuters).

${ }^{15}$ An American option is like an European option, except it can be exercised at any time prior to maturity.
} 
Table 1

Expiration dates for ECX option prices

Source: Bloomberg

\begin{tabular}{lll}
\hline \hline Month & Last Trade & Expiration \\
\hline November 2006 & $11 / 22 / 06$ & $11 / 22 / 06$ \\
December 2006 & $12 / 19 / 06$ & $12 / 19 / 06$ \\
December 2007 & $12 / 24 / 07$ & $12 / 24 / 07$ \\
December 2008 & $12 / 10 / 08$ & $12 / 10 / 08$ \\
January 2009 & $1 / 21 / 09$ & $1 / 21 / 09$ \\
February 2009 & $2 / 18 / 09$ & $2 / 18 / 09$ \\
December 2009 & $12 / 9 / 09$ & $12 / 9 / 09$ \\
December 2010 & $12 / 15 / 10$ & $12 / 15 / 10$ \\
December 2011 & $12 / 14 / 11$ & $12 / 14 / 11$ \\
December 2012 & $12 / 14 / 12$ & $12 / 14 / 12$ \\
\hline \hline
\end{tabular}

\subsubsection{Volume analysis}

The volume of option prices traded from October 13, 2006 to January 162009 for the futures contracts of maturity December 2007 to December 2012 are presented in Table 7, along with the average volume contract for each strike.

The total volume of option prices traded is equal to $235 \mathrm{Mton}$ of $\mathrm{CO}_{2}$ for the December 2008 contract, and to $73 \mathrm{Mton}$ of $\mathrm{CO}_{2}$ for the December 2009 contract. Calls are more actively traded than puts with an average volume of, respectively, 163 Mton and 72 Mton of $\mathrm{CO}_{2}$ for the December 2008 contract. This pattern is reversed for the December 2009 contract with a total volume of calls and puts traded equal to, respectively, $31 \mathrm{Mton}$ and $42 \mathrm{Mton}$ of $\mathrm{CO}_{2}$. This latter result may be explained by anticipations of carbon price decreases due to economic uncertainties by market participants. We may notice that the volume of call prices exchanged is clustered around the strikes ranging between $€ 25$ and $€ 28$. Conversely, the volume of put prices exchanged is clustered around the strikes ranging from $€ 15$ to $€ 24$. These asymmetries reflect the hedging strategies constructed by market agents to reduce the risk of their position with regard to high/low carbon price changes. They also reflect the uncertainties affecting the allowance market concerning the possible range of price changes in a moving institutional context.

\section{Data}

Our sample period goes from April 22, 2005 to April 04, 2008. We gather a full sample of 756 daily observations, with 378 daily observations in each sub-sample before and after the introduction of option prices on October 13, 2006. The source of the data is ECX, Bloomberg and Reuters.

\subsection{Carbon Price}

For carbon allowances, we use daily futures and option prices for the December 2008-2009 contracts traded in $€ /$ ton of $\mathrm{CO}_{2}$ on ECX. Figure 1 shows the futures price development for contracts of maturities December 2008 and 2009 from April 22, 2005 to January 16, 2009. We may observe that 

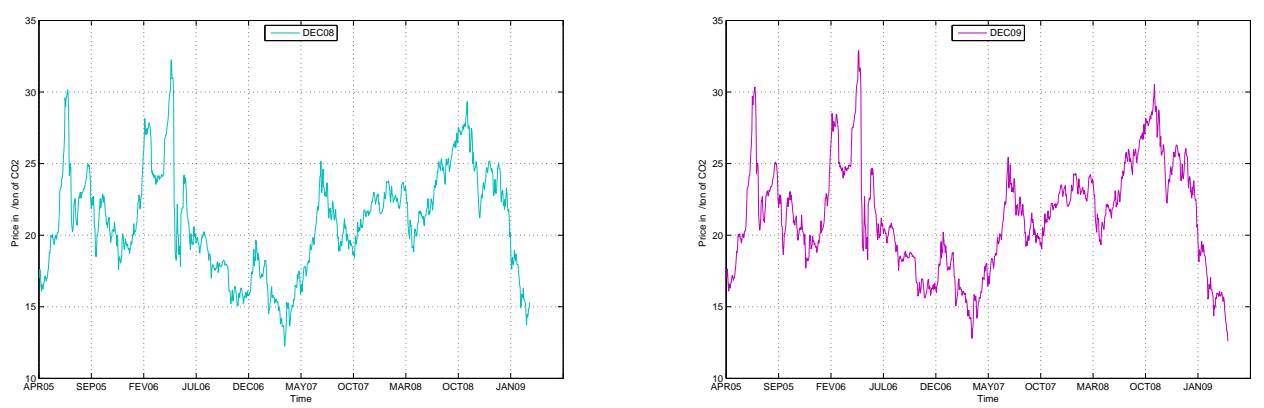

Figure 1

Carbon futures prices of maturities December 2008 (left) and 2009 (right) from April 22, 2005 to January 16, 2009

Source: European Climate Exchange
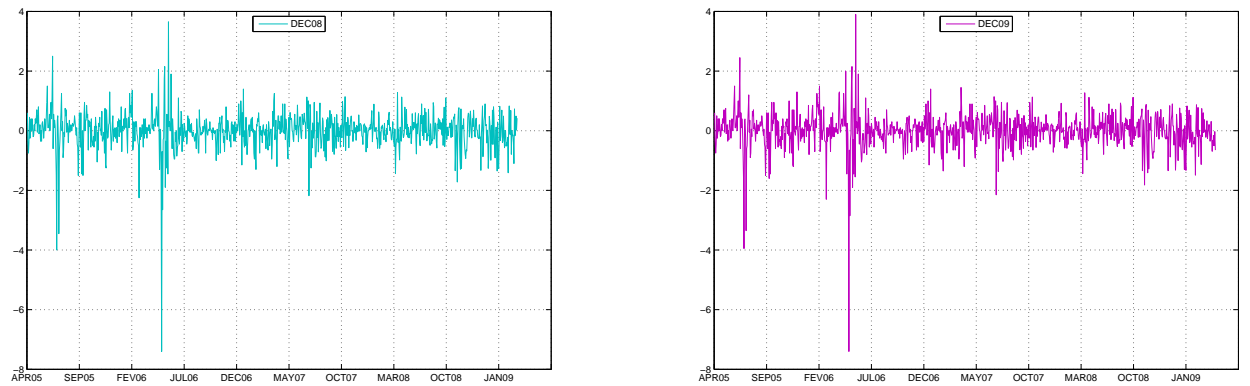

Figure 2

Returns on ECX Carbon Futures Prices of maturities December 2008 (left) and 2009 (right) from April 22, 2005 to January 16, 2009

futures prices for delivery during Phase II (2008-2012) proved to be much more reliable than futures prices for delivery during Phase I (2005-2007) due to the banking restrictions enforced between the two Phases (Alberola and Chevallier, 2009). Besides, we note that post-2007 futures convey a coherent price signal - around $20 €$ /ton of $\mathrm{CO}_{2}$ - throughout the historical available data for the second phase of the scheme. The futures price development features a lower bound around $15 € /$ ton of $\mathrm{CO}_{2}$ in April 2007 , and an upper bound around $35 € /$ ton of $\mathrm{CO}_{2}$ in November 2008.

Descriptive statistics of ECX futures contracts of maturity December 2008 and 2009 are presented in Table 2. We may observe that ECX futures of all maturities present negative skewness and excess kurtosis ${ }^{16}$. These summary statistics therefore reveal an asymmetric and leptokurtic distribution. ${ }^{17}$

\subsection{Energy Prices}

According to previous literature, energy prices are the most important drivers of carbon prices due to the ability of power generators to switch between their fuel inputs (Delarue et al. (2008), Ellerman

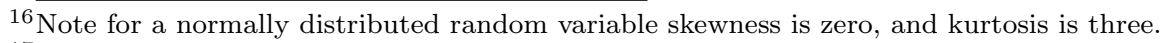

${ }^{17}$ Such a fat-tailed distribution may suggest a GARCH modeling as GARCH models better accommodate excess kurtosis in the data.
} 
Table 2

Descriptive Statistics of ECX EUA Futures Returns and Energy and Global Commodity Markets Returns from April 22, 2005 to January 16, 2009

Source: European Climate Exchange, Reuters

\begin{tabular}{|c|c|c|c|c|c|c|c|}
\hline Full Period & Mean & Median & Max & Min & $\begin{array}{l}\text { Std. } \\
\text { Dev. }\end{array}$ & Skew. & Kurt. \\
\hline \multicolumn{8}{|c|}{ Carbon Futures Returns } \\
\hline$E U A_{D E C 08}$ & -0.0018 & 0.0200 & 3.6500 & -7.4000 & 0.6149 & -2.2450 & 29.7930936 \\
\hline$E U A_{D E C 09}$ & -0.0047 & 0.0200 & 3.9000 & -7.4000 & 0.6169 & -2.1299 & 29.1426957 \\
\hline \multicolumn{8}{|c|}{ Energy and Global Commodity Markets Returns } \\
\hline Brent & -0.0135 & 0.0381 & 11.0876 & -15.6324 & 1.6227 & -0.8159 & 19.0411830 \\
\hline Coal & 0.0034 & 0.0100 & 8.2900 & -5.5600 & 0.6566 & 1.1207 & 46.3338830 \\
\hline$C R B$ & 0.0619 & 0.4000 & 30.5700 & -38.8100 & 5.3023 & -0.8334 & 12.9586830 \\
\hline CleanDark & 0.0151 & -0.0250 & 50.1700 & -40.1400 & 4.2297 & 1.4064 & 50.5866830 \\
\hline Ngas & 0.0009 & -0.0700 & 42.4500 & -20.5200 & 3.2438 & 3.3141 & 49.2934830 \\
\hline Power & 0.0121 & -0.0200 & 43.7100 & -39.7800 & 4.1482 & 0.5050 & 44.8046830 \\
\hline CleanSpark & 0.0137 & -0.0300 & 45.5000 & -42.2200 & 4.8714 & 0.0109 & 33.3175830 \\
\hline Switch & 0.0001 & 0.0001 & 0.0500 & -0.0300 & 0.0053 & 1.3380 & 18.8594830 \\
\hline
\end{tabular}

Note: $E U A_{D E C 08}$ to $E U A_{D E C 14}$ refer to the carbon futures returns of maturity December 2008 to December 2014, CRB to the Reuters/Commodity Research Bureau Futures Index, StdDev. refers to the standard deviation, Skew. refers to the skewness, Kurt. refers to the kurtosis, and $N$ refers to the number of observations.

and Feilhauer (2008)). This option to switch from natural gas to coal in their inputs represents an abatement opportunity to reduce $\mathrm{CO}_{2}$ emissions in the short term. High (low) energy prices contribute to an increase (decrease) of carbon prices. This logic is described by Kanen (2006) who identifies brent prices as the main driver of natural gas prices which, in turn, affect power prices and ultimately carbon prices. Bunn and Fezzi (2007) also identify econometrically that carbon prices react significantly to a shock on gas prices in the short term. Descriptive statistics for energy and global commodity markets returns may also be found in Table 2 .

\subsubsection{Brent, Natural Gas, and Coal Prices}

For energy prices, we use the daily Intercontinental Exchange (ICE) Crude Oil Brent Free-of-Board in $\$$ /barrel, the daily ICE Natural Gas 1-Month Forward contract traded in UK pence/Therm, and the daily coal futures Month Ahead price CIF ARA ${ }^{18}$ traded in $€ /$ ton. Price series are converted to $€$ using the daily exchange rate provided by the European Central Bank.

Figure 3 presents the price development for the Zeebrugge natural gas next month, Rotterdam coal futures, and NYMEX crude oil futures price series from April 22, 2005 to January 16, 2009. Natural gas prices exhibit a strong volatility compared to coal prices. In November 2005 and September 2008, natural gas prices soared to $90 € / \mathrm{MWh}$, and steadily decreased afterwards to $40 € / \mathrm{MWh}$ in February 2008 and December 2008. The competitiveness of natural gas compared to coal may be more specifically captured during the period going from December 2006 to July 2007. The brent price series peaked over $80 € /$ barrel from May to August 2008 .

${ }^{18} \overline{\mathrm{CIF}}$ ARA defines the price of coal inclusive of freight and insurance delivered to the large North West European ports, e.g. Amsterdam, Rotterdam or Antwerp. 


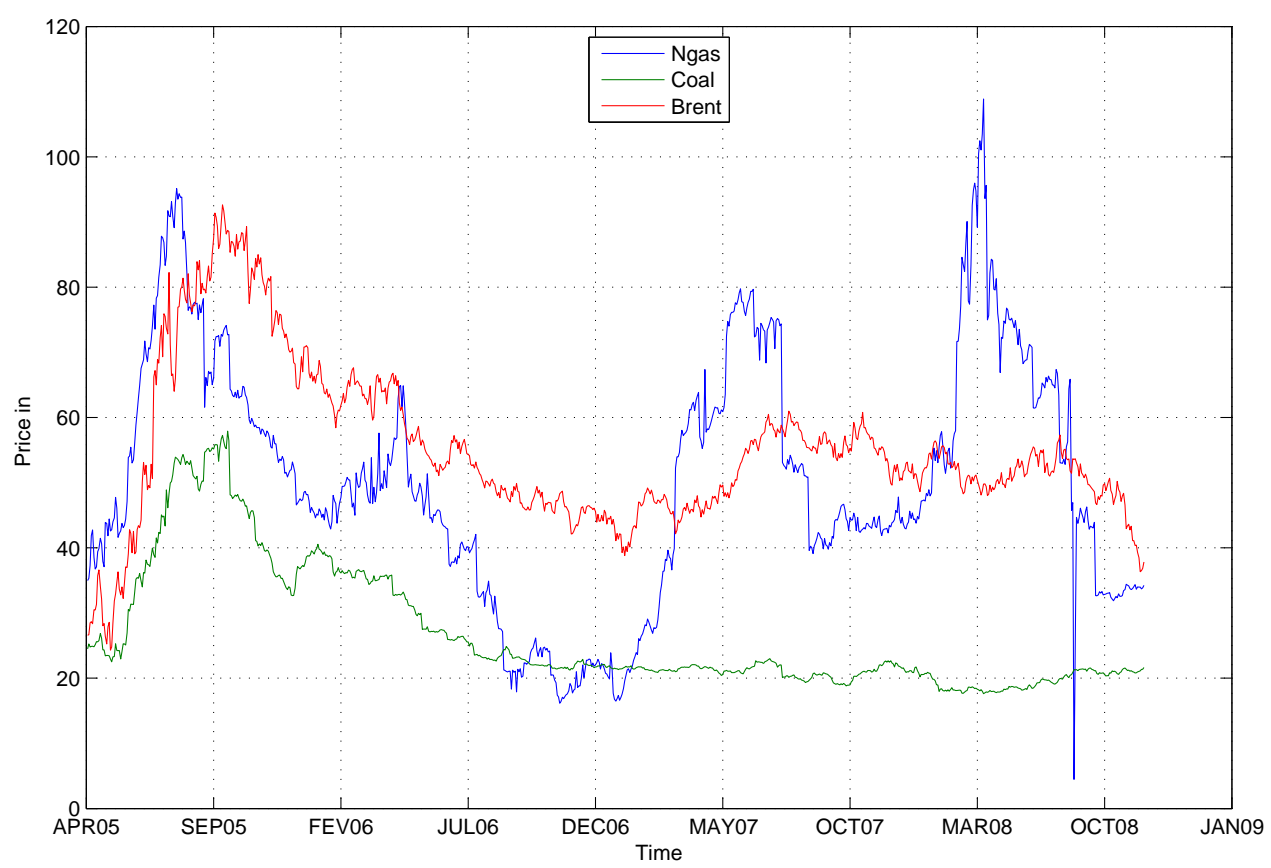

Figure 3

Zeebrugge natural gas, Rotterdam coal futures, and NYMEX crude oil futures prices from April 22, 2005 to January 16, 2009 Source: Reuters

\subsubsection{Power, Clean Spark, Clean Dark, and Switch Prices}

The price of electricity Powernext (elec in $€ / M W h$ ) is the contract of futures Month Ahead Base. To take account of abatement options for energy industrials and relative fuel prices, three specific spreads are included.

First, the Clean Dark Spread (clean dark spread expressed in $€ / M W h$ ) represents the difference between the price of electricity at peak hours and the price of coal used to generate that electricity, corrected for the energy output of the coal plant and the costs of $\mathrm{CO}_{2}$ :

$$
\text { clean dark spread }=\text { elec }-\left(\operatorname{coal} * \frac{1}{\rho_{\text {coal }}}+p_{t} * E F_{\text {coal }}\right)
$$

with $\rho_{\text {coal }}$ the net thermal efficiency of a conventional coal-fired plant. ${ }^{19}$, and $E F_{\text {coal }}$ the $\mathrm{CO}_{2}$ emissions factor of a conventional coal-fired power plant ${ }^{20}$

Second, the Clean Spark Spread (clean spark spread expressed in $€ / M W h$ ) represents the difference between the price of electricity at peak hours and the price of natural gas used to generate that electricity, corrected for the energy output of the gas-fired plant and the costs of $\mathrm{CO}_{2}$ :

\footnotetext{
${ }^{19}$ i.e. $35 \%$ according to Reuters.

${ }^{20}$ i.e. $0.95 \mathrm{tCO}_{2} / \mathrm{MWh}$ according to Reuters.
} 


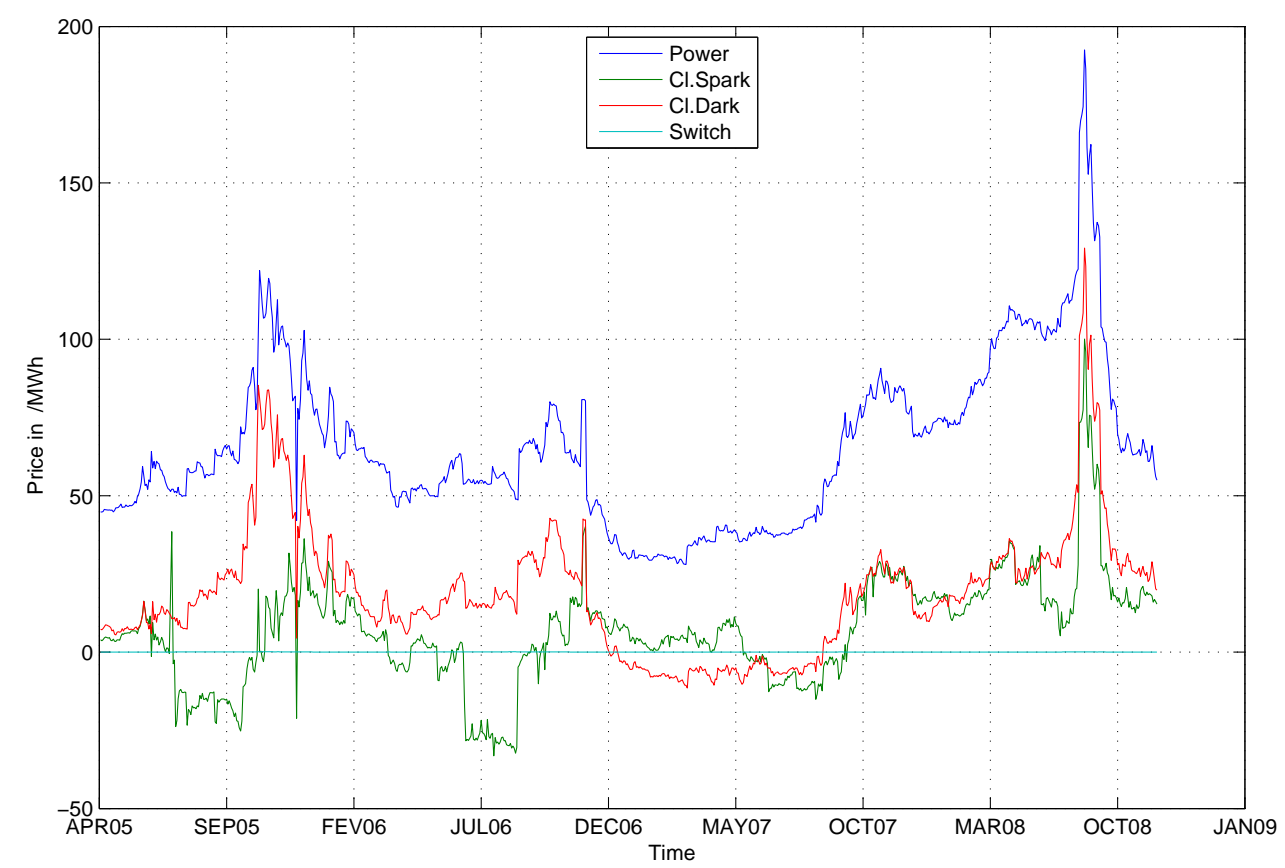

Figure 4

Powernext electricity futures, Clean Spark Spread, Clean Dark Spread, and Switch prices from April 22, 2005 to January 16, 2009

Source: Reuters

$$
\text { clean spark spread }=\text { elec }-\left(\text { ngas } * \frac{1}{\rho_{\text {ngas }}}+p_{t} * E F_{n g a s}\right)
$$

with $\rho_{\text {ngas }}$ the net thermal efficiency of a conventional gas-fired plant. ${ }^{21}$, and $E F_{\text {ngas }}$ the $\mathrm{CO}_{2}$ emissions factor of a conventional gas-fired power plant ${ }^{22}$

Third, the switch price of $\mathrm{CO}_{2}$, expressed in $€ / M W h$, is used as a proxy of the abatement cost:

$$
\text { switch }=\frac{\text { cost }_{\text {ngas }} / M W h-\text { cost }_{\text {coal }} / M W h}{t C O 2_{\text {coal }} / M W h-t C O 2_{\text {ngas }} / M W h}
$$

with cost $_{\text {ngas }}$ the production cost of one MWh of electricity on base of net $\mathrm{CO}_{2}$ emissions of gas in $€ / \mathrm{MWh}$, cost $_{\text {coal }}$ the production cost of one MWh of electricity on base of net $\mathrm{CO}_{2}$ emissions of coal in $€ / \mathrm{MWh}, t C O 2_{\text {coal }}$ the emissions factor in $\mathrm{CO}_{2} / \mathrm{MWh}$ of a conventional coal-fired plant, and $t C O 2_{n g a s}$ the emissions factor in $\mathrm{CO}_{2} / \mathrm{MWh}$ of a conventional gas-fired plant as detailed above.

The Switch price represents the fictional daily price of $\mathrm{CO}_{2}$ that establishes the equilibrium between the Clean Dark and Clean Spark spreads. It is advantageous in the short term to switch from coal to natural gas, when the daily $\mathrm{CO}_{2}$ price is above the Switch price, and conversely.

As shown in Figure 4, the use of coal appeared more profitable than natural gas during 2005-2006. Since the beginning of 2007, the difference between both spreads has been narrowing. This situation

21 i.e. $49.13 \%$ according to Reuters.

${ }^{22}$ i.e. $0.41 \mathrm{tCO}_{2} / \mathrm{MWh}$ according to Reuters. 
therefore provides incentives for power operators to switch the use of natural gas instead of coal, as represented by the Switch price series. Besides, we may note a peak in the price of electricity from September to November 2008.

\subsection{Global commodity markets}

Several indices may be used to capture the influence of risk factors linked to global commodity markets. The main index which is used as the barometer of commodity prices is the Reuters/Commodity Research Bureau (CRB) Futures Index. This index is composed of 17 commodities in different sectors such as energy, grains, industrials, livestock, precious metals and softs. It may be viewed as a broad measure of overall commodity products. $^{23}$

The constituent commodities and the economic weighting of these indices aim at minimizing the idiosyncratic effects of some individual commodity markets. ${ }^{24}$ As a commodity, the dynamics of futures allowance prices are very likely to be impacted by the price volatility on global commodity markets, and thus we include the Reuters/CRB Futures Index as an exogenous factor in our estimates.

Energy and global commodity markets returns are presented in Figure 5.

\subsection{Correlation between energy and global commodity markets}

We are able to alleviate correlation concerns among energy and global commodity markets by looking at the correlation matrix between the returns of potential explanatory variables in Table 3 .

The correlation levels remain low, i.e. strictly inferior to $60 \%$. We thus may use the returns on energy and global commodity markets as potential factors affecting changes in volatility without any problematic collinearities. Since it is possible to have low correlations together with collinearity, we have investigated the presence of multicolinearity by computing the inflation of variance between explanatory variables. These calculations did not reveal serious problematic multicolinearities. ${ }^{25}$

In the next section, we present the econometric methodology used along with our estimation results.

\section{Empirical analysis}

Our econometric methodology may be broadly summarized in four different steps: (i) we estimate a GARCH model with a dummy variable to compare the level of (unconditional) volatility of the underlying allowance market before and after the introduction of the option market; (ii) we include other factors in the variance equation of the GARCH model to control for exogenous effects from relevant variables; (iii) we discuss volatility dynamics issues during sub-periods; and (iv) we finally

\footnotetext{
${ }^{23}$ Other indices coming from brokers in the banking industry may also be used for sensitivity tests purposes. The Dow Jones-American International Group Commodity Index (DJ-AIGCI) is a benchmark for commodity investments composed of 20 commodities within the energy, petroleum, precious metals, industrial metals, grains, livestock and softs sectors. The Standard \& Poor's Commodity Index (SPCI) is a cross section of 17 agricultural and industrial commodities traded in the energy, fibers, grains, meat and livestocks, metals and softs sectors. The Deutsche Bank Commodity Index (DBCI) is composed of six commodities in the crude oil, heating oil, aluminium, gold, wheat and corn industries, and is designed to track the performance of investments in a small set of commodities in a variety of currencies.

${ }^{24}$ See Geman (2005) for a more detailed analysis of the construction, the coverage, the liquidity, and the weighting of each index.

${ }^{25}$ To conserve space, those results are not presented here, and may be obtained upon request to the authors.
} 

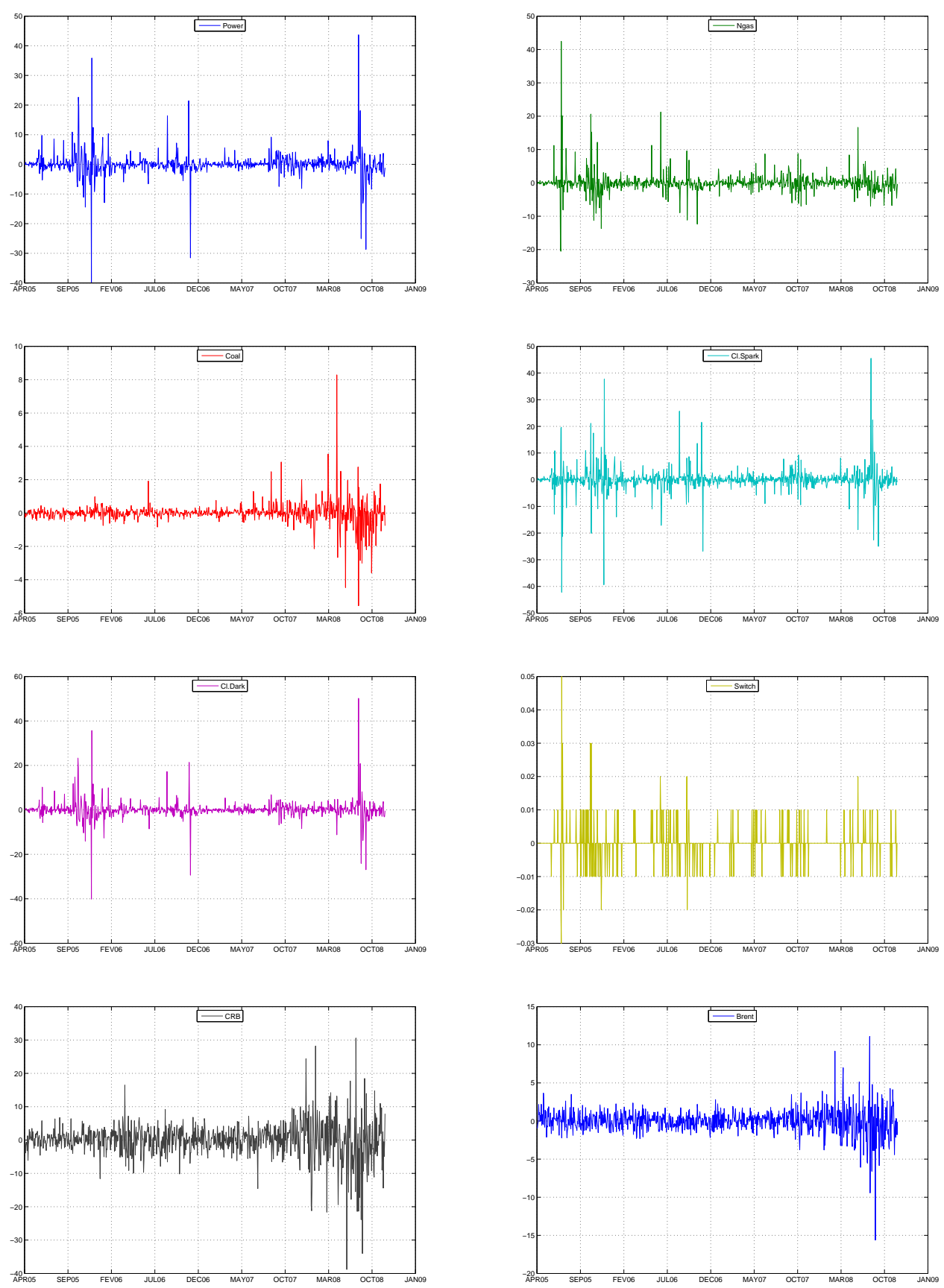

Figure 5

Returns on Energy and Global Commodity Markets Variables from April 22, 2005 to January 16,2009 


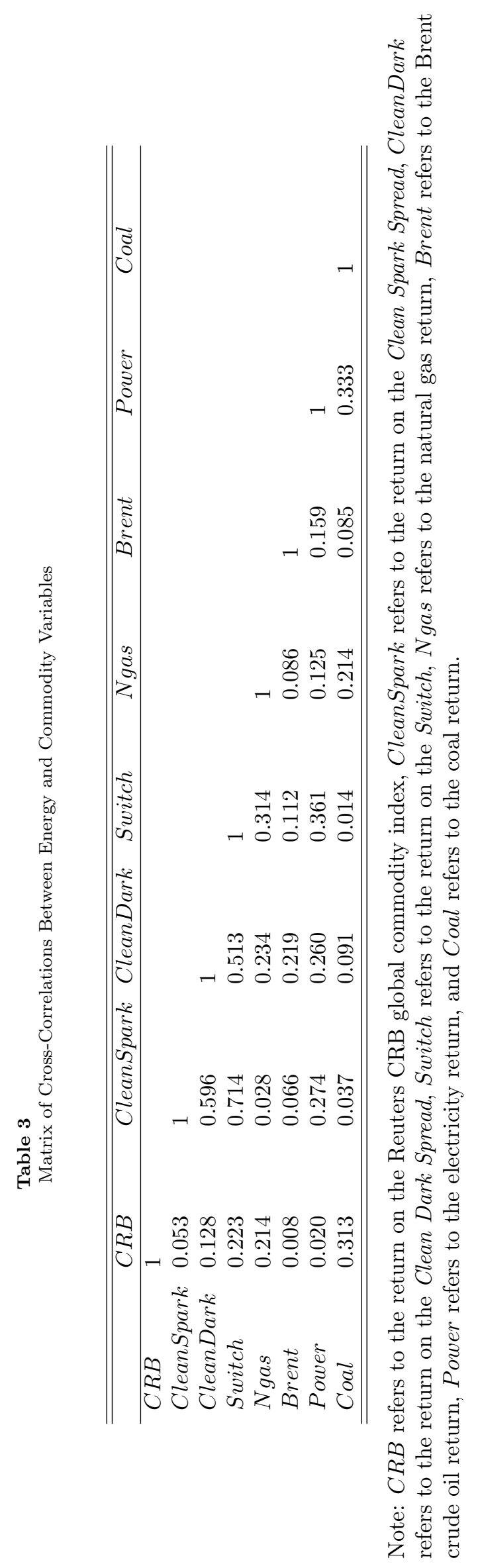


run rolling estimations to further identify the effects of the introduction of the option market on the volatility dynamics of the EU ETS.

\subsection{GARCH model}

The GARCH modeling approach adopted here is common for financial time-series, and has been applied to carbon prices in previous literature (Paolella and Taschini (2008), Benz and Truck (2009)). GARCH models allow to take into account volatility clustering, indicated by fat-tails in the distribution of financial time-series.

The impact of options trading is tested by amending the conditional variance equation of the GARCH model with a dummy variable which takes values 0 for the pre-option period, and 1 for the post-option period. This methodology has been applied by Antoniou and Holmes (1995), Gulen and Mayhew (2000) for financial markets, and Antoniou and Foster (1992) for the crude oil market. ${ }^{26}$ Then, we adopt the structure of a $\operatorname{GARCH}(1,1)$ model:

$$
\begin{gathered}
R_{t}=\beta_{0}+\beta_{1} R_{t-1}+\epsilon_{t} \\
\epsilon_{t} \sim \sqrt{h_{t}} e_{t} \quad \text { with } \quad e_{t} \sim \operatorname{iid}(0,1) \\
h_{t}=E\left(\epsilon_{t}^{2} \mid \phi_{t-1}\right)=\alpha_{0}+\alpha_{1} \epsilon_{t-1}^{2}+\alpha_{2} h_{t-1}+\gamma D F_{t}
\end{gathered}
$$

with $R_{t}$ the daily return on carbon futures prices, $\phi_{t-1}$ is the set of past information, and $\epsilon_{t}$ the error term in Eq. (4). In the conditional variance Eq. (5), $D F_{t}$ is a dummy variable taking the value of 0 before the introduction of the option market, and 1 thereafter. This dummy variable allows to test for the influence of the introduction of option prices on the volatility of the underlying carbon market.

\subsubsection{Estimation}

We first test Eq. (4) and (5) with a $\operatorname{GARCH}(1,1)$ model without the dummy accounting for the introduction of the options market in the variance equation. A preliminary analysis of the returns autocorrelation shows that modeling the conditional mean as an $\operatorname{AR}(1)$ eliminate the autocorrelation for each contract. Those results, presented in Table 4 (rows (1) and (3)), reveal a strongly persistent process, as the sum of $\alpha_{1}$ and $\alpha_{2}$ is close to 1 . This characteristic is a classic feature of financial time-series, and applies for both carbon futures contract of maturity December 2008 and 2009. The time profile of the estimated conditional standard errors from this GARCH model are respectively displayed in Figure 6 for the December 2008 and 2009 contracts. These graphs are very similar for both contracts. During our study period, we observe that the carbon market has been more volatile during the first 300 days, and that the level of volatility is quite lower after April 2006.

\subsubsection{Modeling the option market introduction}

We estimate Eq. (4) and (5) by introducing the dummy variable $D F_{t}$ capturing the changes in volatility due to the introduction of the option market. Recall that $D F_{t}$ takes the value of 0 before

\footnotetext{
${ }^{26}$ Fleming and Ostdiek (1999) also consider the issue of the impact of derivatives trading on the spot crude oil market,
} but using GMM methods as in Bollen (1998). 

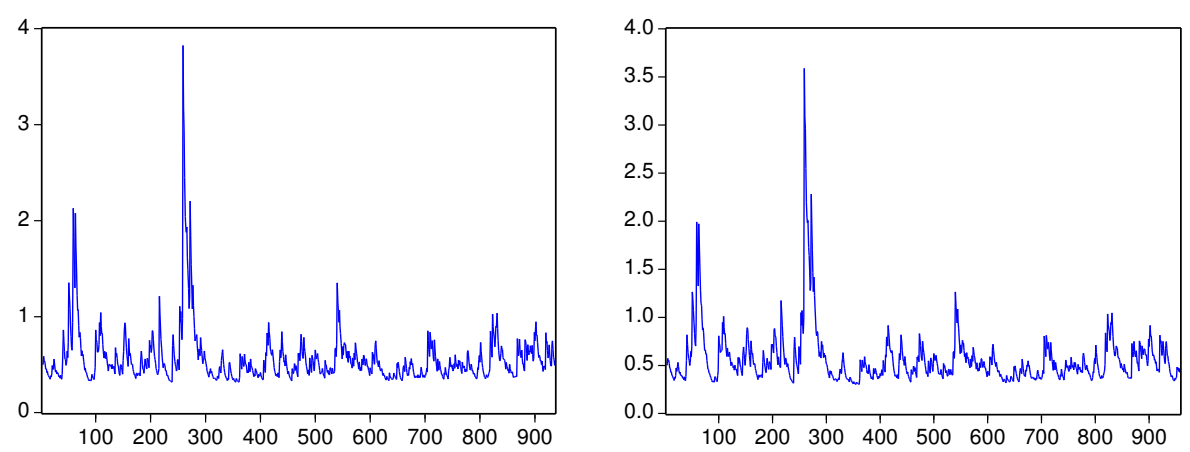

Figure 6

From left to right: conditional standard deviation for the December 08 and 09 returns from a GARCH $(1,1)$

Table 4

GARCH $(1,1)$ model estimates with and without dummy variable for the carbon futures returns of maturity December 2008 and December 2009

\begin{tabular}{lllll}
\hline \hline & \multicolumn{2}{c}{$E U A_{D E C 08}$} & \multicolumn{2}{c}{$E U A_{D E C 09}$} \\
\hline & $(1)$ & $(2)$ & $(3)$ & $(4)$ \\
\hline $\begin{array}{l}\text { Mean equation } \\
\beta_{0}\end{array}$ & $0.0023^{* *}$ & $0.0021^{* *}$ & 0.0020 & 0.0019 \\
& $(0.001)$ & $(0.001)$ & $(0.001)$ & $(0.001)$ \\
$\beta_{1}$ & $0.1398^{* * *}$ & $0.1413^{* * *}$ & $0.1348^{* * *}$ & $0.1342^{* * *}$ \\
& $(0.048)$ & $(0.047)$ & $(0.048)$ & $(0.048)$ \\
\hline Variance equation & & & & \\
$\alpha_{0}$ & $7.74 \mathrm{e}-05^{* * *}$ & $8.33 \mathrm{e}-05^{* * *}$ & $5.41 \mathrm{e}-05^{* * *}$ & $6.18 \mathrm{e}-05 * * *$ \\
& $(1.45 \mathrm{e}-05)$ & $(1.61 \mathrm{e}-05)$ & $(1.24 \mathrm{e}-05)$ & $(1.44 \mathrm{e}-05)$ \\
$\alpha_{1}$ & $0.3039^{* * *}$ & $0.2858^{* * *}$ & $0.2638^{* * *}$ & $0.2541^{* * *}$ \\
& $(0.027)$ & $(0.029)$ & $(0.025)$ & $(0.026)$ \\
$\alpha_{2}$ & $0.6544^{* * *}$ & $0.6710^{* * *}$ & $0.7120^{* * *}$ & $0.7193^{* * *}$ \\
& $(0.037)$ & $(0.039)$ & $(0.034)$ & $(0.035)$ \\
$D_{F}$ & & $-1.85 \mathrm{E}-05$ & & $-1.62 \mathrm{E}-05$ \\
& & $(1.26 \mathrm{E}-05)$ & & $(1.05 \mathrm{E}-05)$ \\
\hline LL & 1680.86 & 1681.38 & 1694.26 & 1694.92
\end{tabular}

Notes: The dependent variables are the EUA carbon futures return for the contract of maturity December 2008 and December 2009 , depending on the column under consideration. Other variables are explained in eq(4) and (5). Standard errors in parenthesis. ${ }^{* * *}$ indicates significance at $1 \%, * *$ at $5 \%$ and $*$ at $10 \%$. LL refers to the log-likelihood. 
the introduction of the options market on October 13, 2006, and 1 thereafter.

Estimation results are presented in Table 4 (rows (2) and (4)). ${ }^{27}$ In Table 4 , rows (2) and (4), we may observe that $D F_{t}$ is not significant at any statistical level. The estimated conditional variances do not differ from the GARCH model without dummy, and thus are not reproduced. While options enable a more complete and liquid market, and a greater flexibility for market participants to hedge their position on the carbon market, they do not seem to have a significant impact on the level of volatility in the futures market. The latter result does not imply however necessarily that the dynamic component of volatility has not been impacted, as will be discussed below. Indeed, it is worth noting that the estimation results obtained in Table 4 concerning the introduction of the option market may be driven by exogenous factors affecting the volatility of carbon futures returns. In other words, a change in the level of the volatility may be hidden by the presence of other risk factors. To deal with this issue, we now introduce exogenous factors in the variance equation of the GARCH model.

\subsection{Exogenous variables in the conditional variance equation}

One problem in Section 4.1 is that the date of the dummy variable is chosen a priori. Of course, this choice is intuitive since we are interested in modeling how the introduction of the option market affects volatility in the EU ETS. However, the impact of the introduction of the option market may have arisen at a date different from its official opening. Furthermore, other structural breaks may have affected the carbon market and the dynamics of conditional volatility. Detecting these breaks appears crucial to obtain a correct modeling of the conditional standard error. To do so, we implement below a test for structural breaks in the unconditional variance at unknown location.

\subsubsection{Structural breaks in the unconditional variance}

Inclán and Tiao (1994) and Sansó, Aragó and Carrion (2004) have proposed a test for detecting a break in the unconditional variance at unknown date. ${ }^{28}$

Our sample of returns $\left\{R_{t}\right\}_{t=1}^{T}$ contains $T$ observations. The test statistic is $A I T=\sup _{k}\left|T^{-0.5} G_{k}\right|$ where $G_{k}=\hat{\lambda}^{-0.5}\left[C_{k}-(k / T) C_{T}\right], C_{k}=\sum_{t=1}^{k} R_{t}^{2}, \hat{\lambda}=\hat{\gamma}_{0}+2 \sum_{l=1}^{m}\left[1-l(m+1)^{-1}\right] \hat{\gamma}_{l}, \hat{\gamma}_{l}=$ $T^{-1} \sum_{t=l+1}^{T}\left(R_{t}^{2}-\hat{\sigma}^{2}\right)\left(\left(R_{t-l}^{2}-\hat{\sigma}^{2}\right), \hat{\sigma}^{2}=T^{-1} C_{T}\right.$. $\hat{\gamma}$ represents a nonparametric adjustment factor used to correct for non dependent processes. It is based on a Bartlett kernel with the lag truncation parameter $m .{ }^{29}$ The value of $k$ that maximises $\left|T^{-0.5} G_{k}\right|$ is the estimate of the break date. Critical values are given in Sansó, Aragó and Carrion (2004).

Inclán and Tiao (1994) developed the Iterated Cumulative Sum of Squares (ICSS) algorithm for detecting multiple breaks in variance. ${ }^{30}$ We apply this algorithm to our AIT statistics to find possible break dates in the unconditional variance of returns.

The AIT test statistic and the ICSS algorithm leads us to detect five breaks in the unconditional

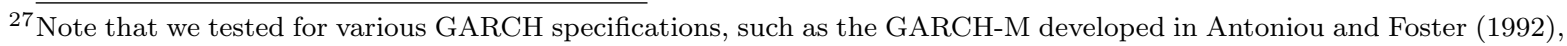
which is convenient for the modeling of a time-varying risk premium. None of them provided superior results. Similarly, various innovation distributions have been implemented (Student $t$, asymmetric Student $t$, GED) to better accommodate residual kurtosis, without further improving the results presented here.

${ }^{28}$ Tests for breaks in the unconditional variance have been recently extended by Andreou and Ghysels (2002). See also Rapach and Strauss (2008).

${ }^{29}$ The lag truncation parameter is chosen as $m=E\left[A(T / 100)^{1 / 4}\right]$ where $\mathrm{T}$ is the number of observations.

${ }^{30} \mathrm{~A}$ complete description of this algorithm can be found in their paper. 


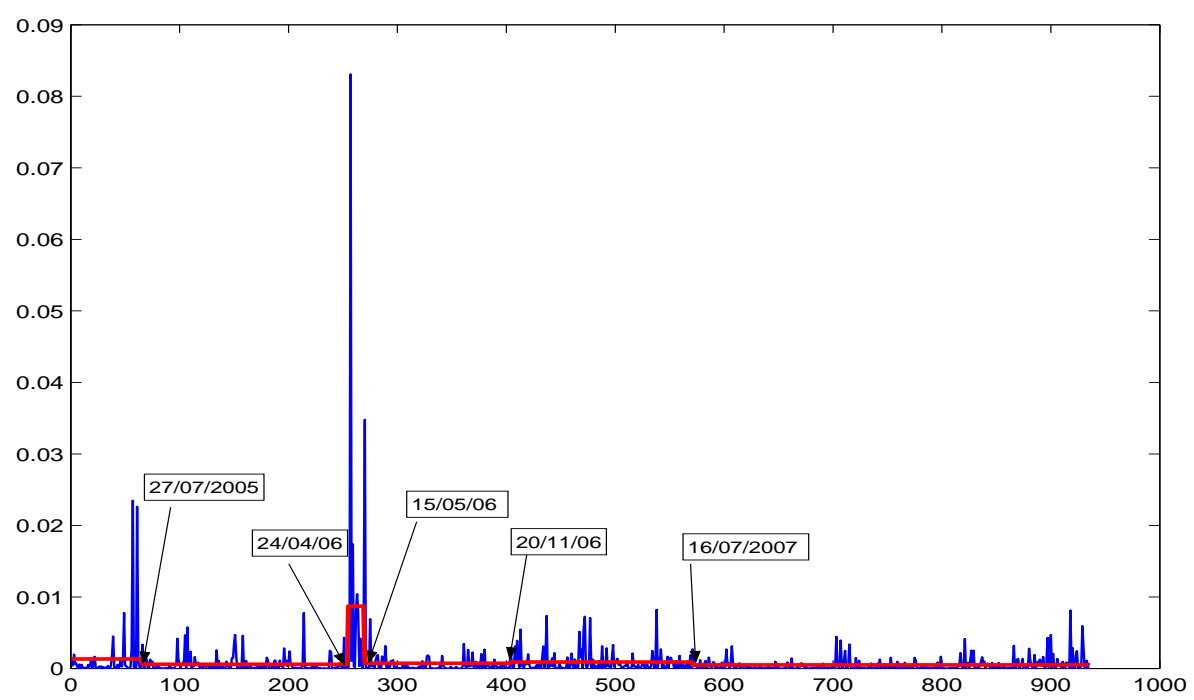

Figure 7

Unconditional variances with break

Note: the blue line represents the squared returns and the red line represents the time profile of the sample variance for the different periods detected from the breaks.

volatility. Figure 7 shows these breaks with their date. This graph also displays the time profile of the sample unconditional variance for the six periods defined by these breaks and the squared returns, considered as a proxy for the shocks hitting the market.

One obvious break in unconditional volatility occurs during the third (and shortest) period from $t=24 / 04 / 06$ to $t=15 / 05 / 06$. During this time period, the market is highly volatile, as reflected by the high values of the squared returns. The sample variance reaches its highest value for this time period. This increase in unconditional variance can be connected with the first compliance break in the time-series of $\mathrm{CO}_{2}$ returns due to the verification of 2005 emissions in April 2006 (Alberola et al. $(2008))$.

We identify two periods where the unconditional volatility increases: the first one going from the beginning of the sample to $t_{1}=27 / 7 / 06$, and the second one from $t_{4}=20 / 11 / 06$ to $t_{5}=16 / 07 / 0 \%$. We observe however that during these periods the sample variance does not increase significantly, and thus we do not further comment these breaks. In addition, no increase in volatility is detected using the algorithm around the time options begin to be traded.

In what follows, to control for the sharp increase in volatility due to the 2006 compliance event, we include the dummy variable $D_{A P R 06}$ which takes the value of 1 during the period going from April 25 to June 23, 2006, and 0 otherwise. This variable reflects the institutional development of the EU ETS that occurred in April 2006 during Phase I (Alberola et al., 2008).

\subsubsection{Introducing exogenous variables}

As highlighted in previous literature (Christiansen et al. (2005), Mansanet-Bataller et al. (2007), Alberola et al. (2008), Chevallier (2009)), the main risk-driving factors on the carbon market are linked to institutional decisions and energy prices. Another source of risk may be linked to the 
variation of global commodity markets, which may be captured by various indices.

To take into account the impact of these factors on the volatility of carbon futures (besides considering the impact of the option market), we include the volatility of several energy- and commodity-related factors. We compute the standard deviations by using a moving window of 25 days (about one trading month) for all factors described in the data section. This methodology is in line with Hadsell and Shawky (2006) and Oberndorfer (2008), and has more formal support than "de-meaning" the mean equation (as in Bologna and Cavallo (2002) for instance).

For energy variables, we use the volatility of returns on Brent, coal and natural gas prices, as well as the volatility of clean dark and clean spark spreads and the switch price, to proxy for the influence of power producers' fuel-switching behavior on carbon price changes. The relationship between carbon price changes and power producers' fuel-switching behavior appears especially important to bear in mind. Fuel-switching constitutes an important determinant of the $\mathrm{CO}_{2}$ price, given the proportion of allowances distributed to the power sector, and the arbitrages being made by producers concerning their energy-mix including the $\mathrm{CO}_{2}$ costs (Delarue et al. (2008), Ellerman and Feilhauer (2008)). For global commodity markets, we include the Reuters/Commodity Research Bureau (CRB) index.

We test below for the potential impact of vol brent, vol gas, vol coal, vol power, vol clean spark, vol clean dark, vol switch, and vol CRB on ECX futures returns volatility modelled using a GARCH framework, by including the estimated volatility of returns of these potential explanatory variables into the variance equation.

\subsubsection{Results}

Equation (5) is modified as follows:

$$
h_{t}=\alpha_{0}+\alpha_{1} \epsilon_{t-1}^{2}+\alpha_{2} h_{t-1}+\gamma D F_{t}+\varphi X_{t}
$$

with $X_{t}$ a vector of exogenous variables including the dummy variable $D_{A P R 06}$ for the April 2006 structural break, estimated standard deviations for energy and the $C R B$ variables.

As shown in Table 5, estimates from our extended model feature the statistical significance of several factors for the December 2009 (rows (5) to (8)) contract and for the December 2008 contract (rows (1) to (4)). Some of these significant variables are not the same for both contracts and their significance is more robust for the December 2009 contract.

Concerning energy variables, vol coal and vol clean spark are significant for the December 2008 contract while vol oil, vol clean spark and vol clean dark significantly impact the volatility of the December 2009 futures contract. The rationale behind the negative role of coal on $\mathrm{CO}_{2}$ price volatility is that, when confronted to a rise of the price of coal relative to other energy markets, firms have an incentive to adapt their energy mix towards less $\mathrm{CO}_{2}$ intensive sources, which yields to less needs of EUAs. This result is conform to previous literature (Mansanet-Bataller et al. (2007), Alberola et al. (2008)). The negative sign of vol spark for both contracts may be explained by the rather decreasing price pattern of natural gas by contrast to coal during our sample period. vol oil positively impacts the volatility returns of $\mathrm{CO}_{2}$ prices for the December 2009 contract. This positive impact can result from the fact that oil is an input of installations covered by the ETS and that changes in its price also affect 


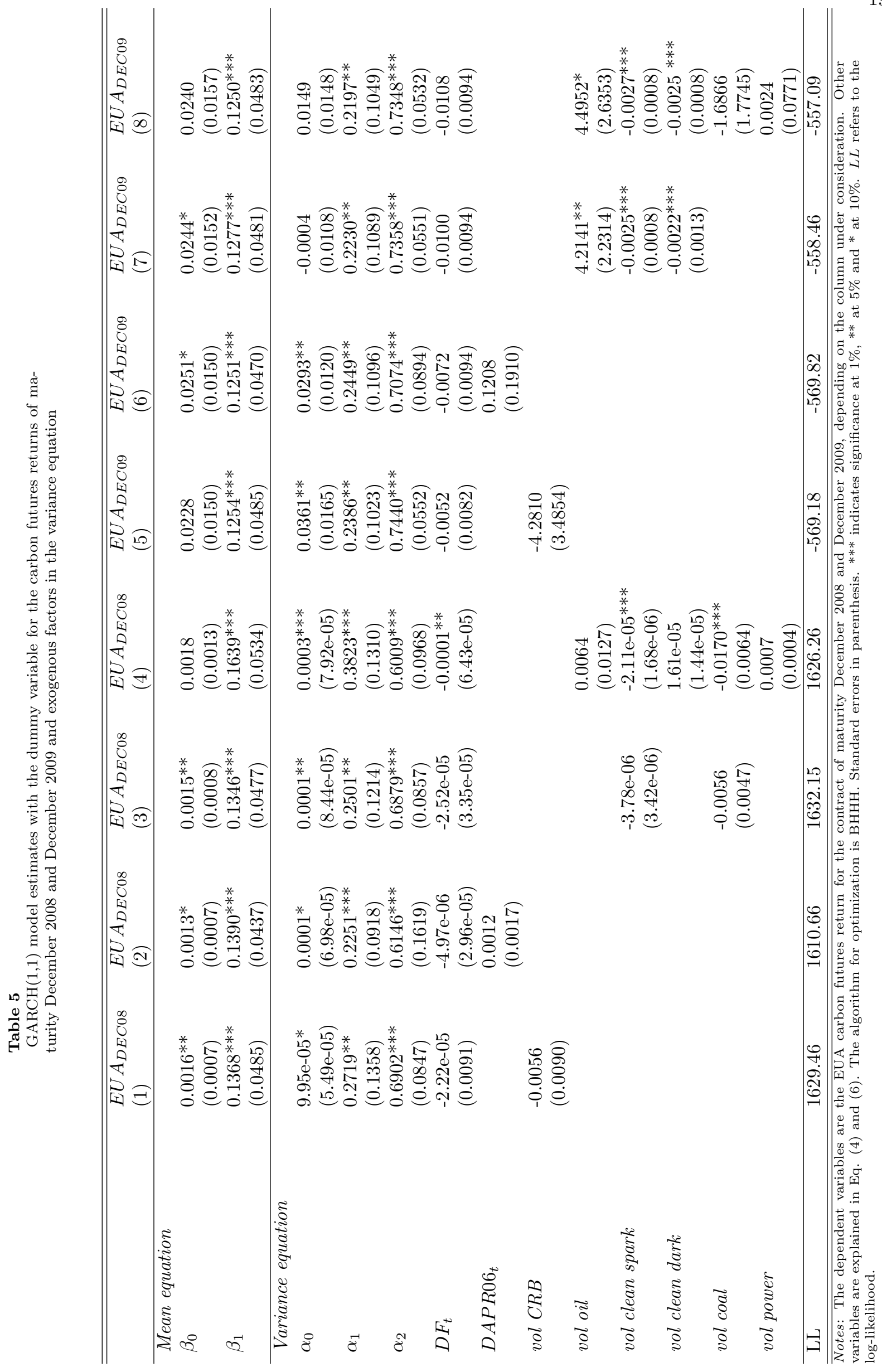



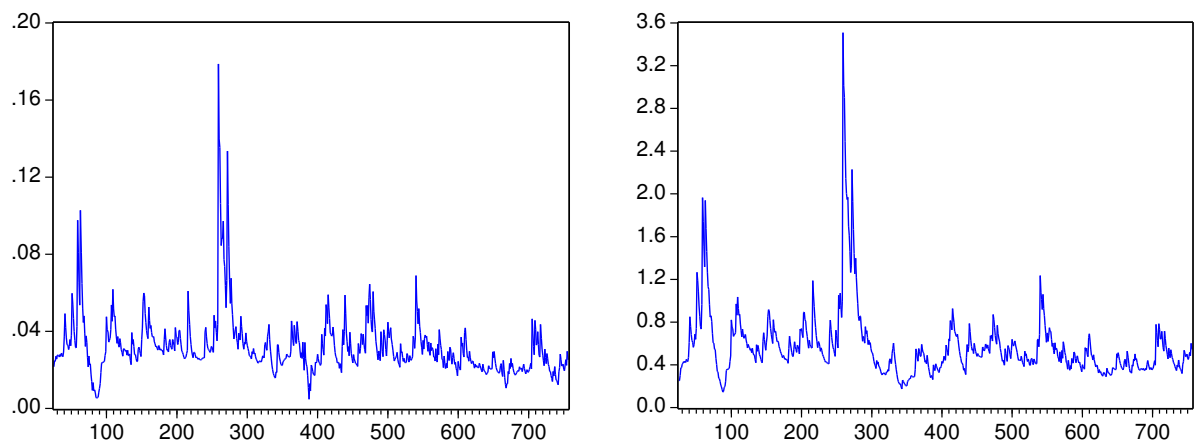

\section{Figure 8}

From left to right: conditional standard deviation for the December 08 and 09 returns from a GARCH $(1,1)$ with a dummy for the option market

economic activity. Therefore, an increase in oil price volatility induces uncertainty about economic perspectives which can increase volatility on the $\mathrm{CO}_{2}$ market. Note that neither the $D_{A P R 06}$ dummy for institutional developments, nor the $C R B$ proxy for global commodity markets are statistically significant.

To conclude, we have shown that even after controlling for other relevant energy, institutional and risk factors, the $D F_{t}$ dummy variable accounting for the introduction of the option market remains insignificant. This result is robust to the introduction of factors known to have an influence, such as institutional decisions, energy and global commodity markets (Christiansen et al. (2005), MansanetBataller et al. (2007), Alberola et al. (2008)). Compared to Table 4, $D F_{t}$ is only significant at the $5 \%$ for the December 2008. This finding is however not robust enough to be an evidence of the impact of the option market opening. We therefore conclude that options introduction had no noticeable impact on the unconditional volatility of $\mathrm{CO}_{2}$ returns. The conditional variances for both contracts are displayed in Figure 8 and do not show any decrease in variance in the post "option introduction" period.

\subsection{Sub-period decomposition}

Besides, we estimate GARCH models during two sub-periods to study the changes in volatility dynamics of carbon futures returns before and after the introduction of option prices. According to Antoniou and Foster (1992), this procedure allows to investigate empirically the effects of the introduction of the option market by using both pre- and post-options volatility measures. Here, we do not precisely deal with the impact of the introduction of the option market on the unconditional variance, but rather on its dynamics in the spirit of Antoniou and Foster (1992), who studied the volatility of futures and spot prices for brent crude oil products.

The econometric methodology consists in comparing the GARCH coefficients before (Sample \#1) and after (Sample \#2) the introduction of the option market, by running separate estimates during sub-periods. Estimation results are presented in Table 6 (rows (1) to (4)).

For Sample \#1 (Table 6, rows (1) and (3)), we observe a strongly persistent (near integrated) effect 
Table 6

GARCH(1,1) model estimates before and after the introduction of the option market for the December 2008 and 2009 carbon futures returns

\begin{tabular}{lllll}
\hline \hline & $\begin{array}{l}E U A_{D E C 08} \\
(1)\end{array}$ & $(2)$ & $\begin{array}{l}E U A_{D E C 09} \\
(3)\end{array}$ & $(4)$ \\
\hline $\begin{array}{l}\text { Mean equation } \\
\beta_{0}\end{array}$ & $\begin{array}{l}0.0032^{* *} \\
(0.001)\end{array}$ & $\begin{array}{l}0.0013 \\
(0.001)\end{array}$ & $\begin{array}{l}0.0036^{* *} \\
(0.001)\end{array}$ & $\begin{array}{l}0.0014 \\
(0.001)\end{array}$ \\
$\beta_{1}$ & $\begin{array}{l}0.1777^{* *} \\
(0.080)\end{array}$ & $\begin{array}{l}0.0660 \\
(0.055)\end{array}$ & $\begin{array}{l}0.1825^{* *} \\
(0.079)\end{array}$ & $\begin{array}{l}0.0575 \\
(0.0573)\end{array}$ \\
\hline Variance equation & & & & \\
$\alpha_{0}$ & $0.0001^{* * *}$ & $3.81 \mathrm{e}-05^{* *}$ & $8.19 \mathrm{e}-05^{* * *}$ & $3.57 \mathrm{e}-05^{* *}$ \\
& $(2.07 \mathrm{e}-05)$ & $(1.70 \mathrm{e}-05)$ & $(2.03 \mathrm{e}-05)$ & $(1.46 \mathrm{e}-05)$ \\
$\alpha_{1}$ & $0.6012^{* * *}$ & $0.1188^{* * *}$ & $0.4611^{* * *}$ & $0.1281^{* * *}$ \\
& $(0.050)$ & $(0.0325)$ & $(0.044)$ & $(0.0328)$ \\
$\alpha_{2}$ & $0.4737^{* * *}$ & $0.8203^{* * *}$ & $0.5870^{* * *}$ & $0.8163^{* * *}$ \\
& $(0.039)$ & $(0.050)$ & $(0.043)$ & $(0.046)$ \\
\hline LL & 811.33 & 882.27 & 811.21 & 894.38 \\
\hline \hline
\end{tabular}

Note: The dependent variables are the EUA carbon futures returns for the contracts of maturity December 2008 and December 2009, depending on the column under consideration. Other variables are explained in Eq. (4) and (6). Standard errors in parenthesis. $* * *$ indicates significance at $1 \%, * *$ at $5 \%$ and $*$ at $10 \%$. $L L$ refers to the log-likelihood.

of the variance of the process. For Sample \# 2 (Table 6, rows (2) and (4)), we observe a reduced persistence of shocks from the pre-options to the post-options period. The value of $\alpha_{1}+\alpha_{2}$ is close to 0.90 in Sample \#2, which suggests that the variance process is not integrated (Engle and Bollerslev, 1986).

The second interesting result consists in a decrease in the autoregressive effect of the carbon futures returns, as the coefficients for $\beta_{1}$ go from 0.18 (row (1)) to 0.07 (row (2)) for the December 2008 contract. ${ }^{31}$ The level of the ARCH coefficient, which represents the reaction to new information, is quite low, suggesting that the informational efficiency of the carbon market has decreased, since the variance adjustment following the arrival of new information is slower. We may observe the same pattern with the December 2009 contract, where the coefficients for $\beta_{1}$ go from 0.18 (row (3)) to 0.06 (row $(4))$.

We did not find evidence of the influence of energy variables on the volatility of $\mathrm{CO}_{2}$ returns during sub-periods. Overall, these results suggest that the dynamics of the variance are quite different before and after the introduction of the options market, which may be inferred from GARCH standard deviations plots in Figure 6.

\subsection{Checking the time dependency of the model}

In this section, we use a rolling estimation procedure to detect some change in the dynamics of the conditional volatility. We estimate the same GARCH $(1,1)$ model as in section 4.1.1. for a rolling window of $L=200$ observations. We obtain a sequence of time indexed estimates of the autoregressive coefficient $\left\{\beta_{1 \mid t-L+1, t}\right\}$ and the coefficients of the GARCH model: $\left\{\alpha_{0 \mid t-L+1, t}\right\},\left\{\alpha_{1, t-L+1, t}\right\}$ and

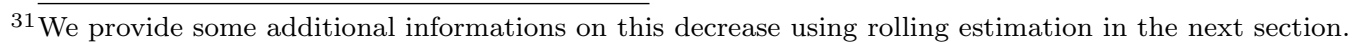


$\left\{\alpha_{2, t-L+1, t}\right\}$ where the $t-L, t$ denotes the sample used for each estimation. Our first estimation is obtained for the sample ending in $t=200=03 / 02 / 2006$.

Figure 9 shows the rolling estimate of the autoregressive coefficient in the conditional mean regression. Figures 10 and 11 show the estimates for the ARCH and GARCH coefficients, respectively. The estimates of the GARCH model clearly show some instability in the estimated coefficients. Changing patterns in the GARCH coefficients therefore indicate changes in the dynamics of conditional volatility.

A first sudden break appears at date $t=258=05 / 05 / 2006$ when the ARCH coefficient rises from 0.4 to 1 , and the GARCH coefficient decreases from around 0.6 to 0.4 . Both of these changes suggest that the impacts of shocks on conditional volatility were especially important during this time period. It coincides with the strong adjustment of market operators' expectations following the publication of the first report of verified emissions by the European Commission (Alberola et al., 2008).

The second change in the estimated coefficient occurs at time $t=451=05 / 02 / 200 \%$. The ARCH coefficient suddenly drops after this date, while the GARCH coefficient increases. This result may also be interpreted in light of the 2007 compliance event, which relates to the verification of 2006 emissions. Market operators have anticipated the release of the report of the European Commission, and therefore the adjustment in market expectations occurs earlier than in 2006. Due to the "youth" of this commodity market and rules in the making concerning the second trading period (2008-2012), the first years of operation of the EU ETS were characterized by strong reversals in expectations around yearly compliance events (Chevallier et al., 2009). ${ }^{32}$ Overall, these rolling windows estimates do not support the view of a strong effect of option introduction on volatility dynamics. Nevertheless, the continuing change in volatility may be partly due to option introduction, despite this hypothesis could hardly be investigated further.

Once agents have integrated this information, we do not observe visually other changes in the estimates of the ARCH coefficient, except for the GARCH coefficient which increases after $t=636=11 / 10 / 200 \%$.

\section{Conclusion}

This article investigates the effects of the introduction of the option market on the volatility of the EU ETS. Following a brief review of key design issues on the EU ETS, we have presented the main characteristics of both the futures and option markets on ECX. Then, we have detailed our econometric methodology, which consists in capturing both unconditional and dynamic components of the volatility of carbon futures returns with GARCH models, rolling estimates and endogenous structural break detection following the introduction of ECX option prices on October 13, 2006. This methodology has been robust to document changes in volatility on equity markets, but has not been applied yet on the carbon market.

Based on daily data from April 2005 to April 2008, our results suggest that volatility has changed during this period but we do find evidence that this change may be due to option introduction. As in Antoniou and Foster (1992), we also find that GARCH estimates are statistically different before and after the introduction of the derivatives market. We have run sensitivity tests with institutional variables, energy and global commodity markets to capture the likely influence of other factors on the

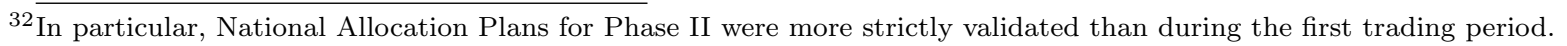




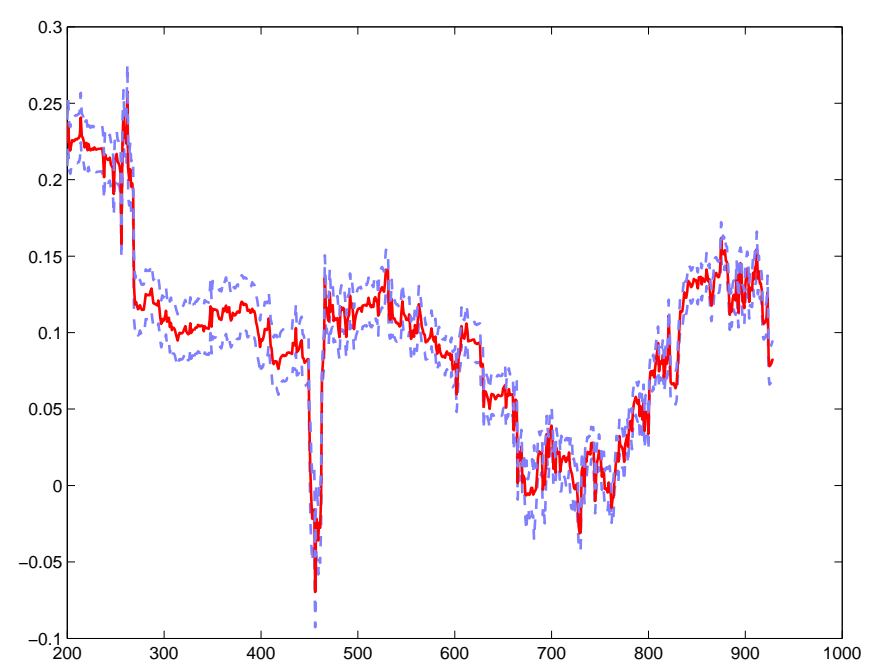

Figure 9

Rolling estimation of the autoregressive coefficient

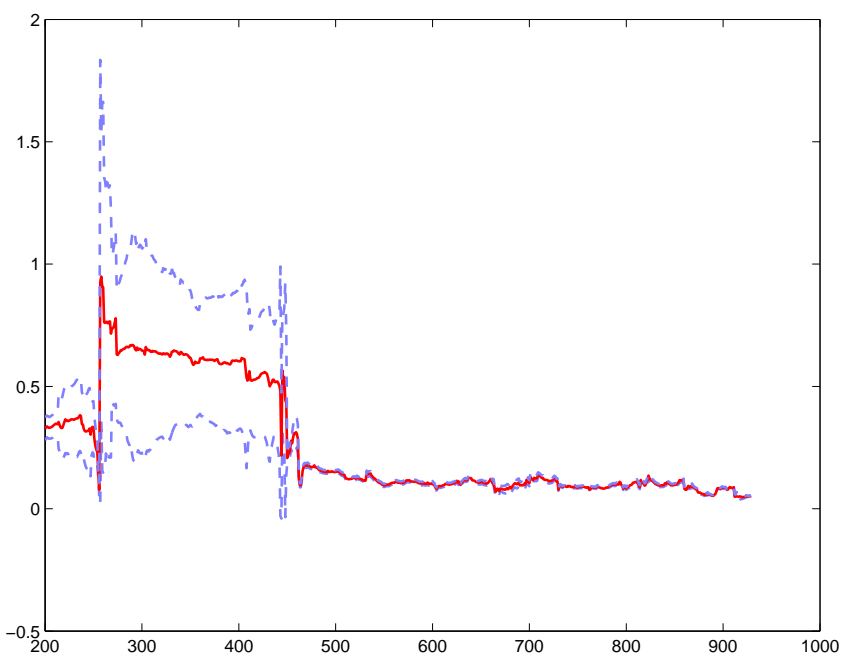

Figure 10

Rolling estimation of the ARCH coefficient

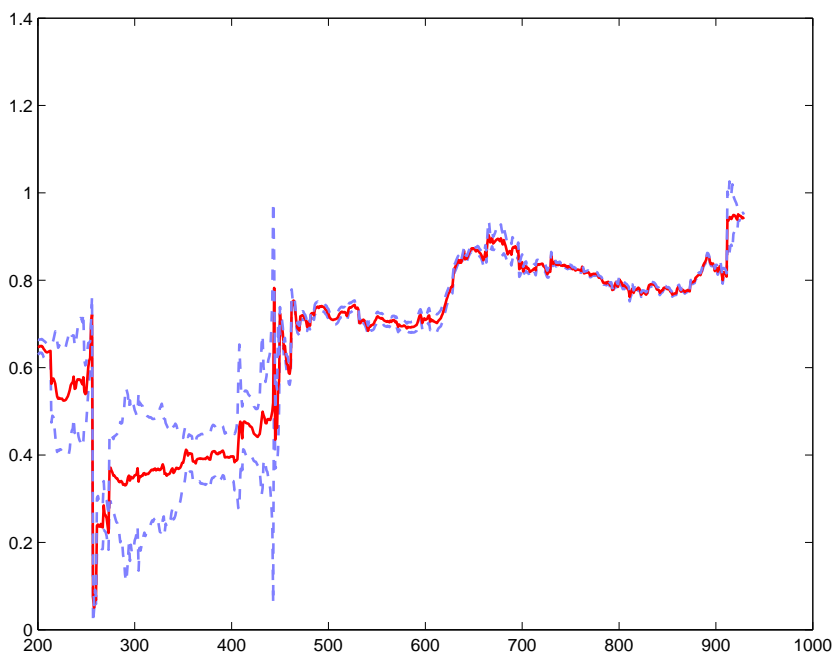

Figure 11

Rolling estimation of the GARCH coefficient 
volatility of futures returns. These tests tend to confirm our preliminary results.

This static analysis is taken one step further with the investigation of the dynamic behavior of $\mathrm{CO}_{2}$ return volatilities. Rolling estimates with a window of 200 days reveal the presence of shocks related to yearly compliance events in the EU ETS during April 2006 and February 2007. Furthermore, the detection of endogenous structural breaks following Inclán and Tiao (1994) yield to the identification of a long-lasting effect that may be due to the introduction of the option market on the unconditional volatility of $\mathrm{CO}_{2}$ returns, which reflects that this impact may not be captured adequately as a "one-off" event. Collectively, these results are conform to the view that options do not systematically impact the stability of the underlying market, but we do not find any evidence of an increase in efficiency due to option introduction, while often argued in the literature.

An potential extension of this work using intraday data may be pursued relying on Liu and Maheu (2009), who test for breaks in realized volatility with Bayesian estimation and an autoregressive modeling of realized volatility (Corsi (2004), Andersen et al. (2007, 2009)). These methods have not been used to detect structural breaks following the introduction of derivative products yet. 


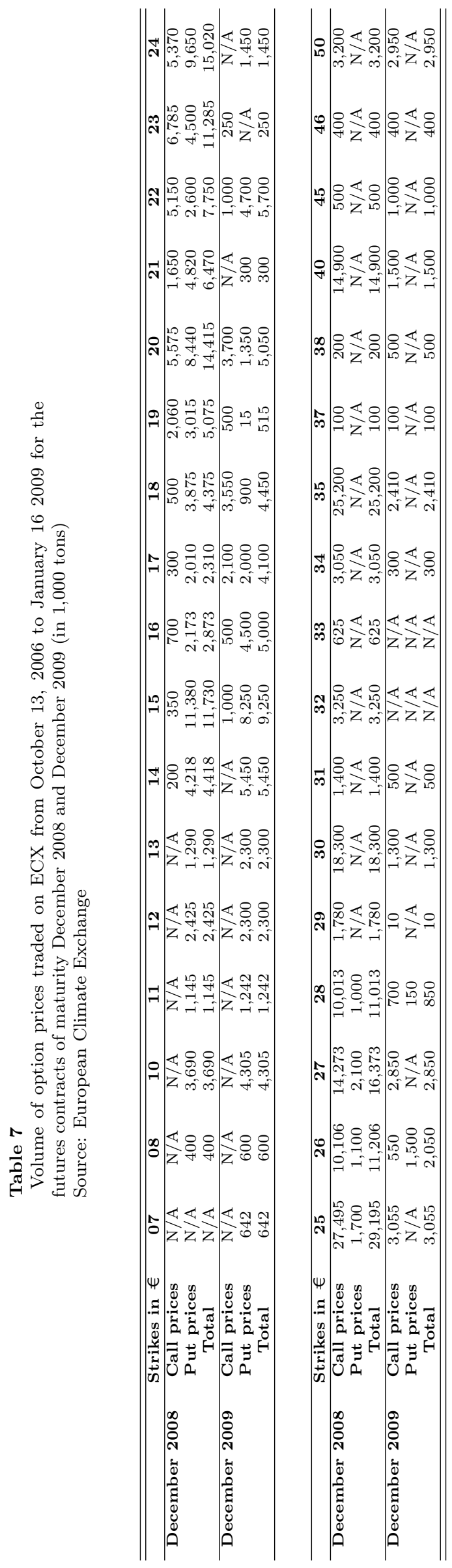




\section{References}

Alberola, E., Chevallier, J., 2009. European carbon prices and banking restrictions: Evidence from Phase I (2005-2007). Energy Journal 30, 51-80.

Alberola, E., Chevallier, J., Chèze, B., 2008. Price drivers and structural breaks in European carbon prices 2005-2007. Energy Policy 36, 787-797.

Alberola, E., Chevallier, J., ChÈze, B., 2009. Emissions Compliances and Carbon Prices under the EU ETS: A Country Specific Analysis of Industrial Sectors. Journal of Policy Modeling 31, 446-462.

Andreou, E., Ghysels, E., 2002a. Rolling sample volatility estimators: some new theoretical, simulation and empirical results. Journal of Business and Economic Statistics 20, 363-376.

Andreou E, Ghysels E., 2002b. Detecting multiple breaks in financial market volatility dynamics. Journal of Applied Econometrics 17, 579-600.

Antoniou, A., Foster, A.J., 1992. The effect of futures trading on spot price volatility: evidence for Brent crude oil using GARCH. Journal of Business Finance and Accounting 19, 473-484.

Antoniou, A., Holmes, P., 1995. Futures trading, information and spot price volatility: evidence for the FTSE-100 Stock Index Futures contract using GARCH. Journal of Banking and Finance 19, 117-129.

BACK, K., 1993. Asymmetric information and options. Review of Financial Studies 6, 435-472.

Benz, E., Truck, S., 2009. Modeling the Price Dynamics of $\mathrm{CO}_{2}$ Emission Allowances. Energy Economics 1, 4-15.

Böhringer, C., Koschel, H., Moslener, U., 2008. Efficiency losses from overlapping regulation of EU carbon emissions. Journal of Regulatory Economics 33, 299-317.

Bollerslev, T, Wooldridge, J.M., 1992. Quasi-maximum likelihood estimation and inference in dynamic models with time-varying covariances. Econometric Reviews 11, 143-172.

Bollen, N.P.B., 1998. A note on the impact of options on stock return volatility. Journal of Banking and Finance 22, 1181-1191.

Bologna, P., Cavallo, L., 2002. Does the introduction of stock index futures effectively reduce stock market volatility? Is the "futures effect" immediate? Evidence from the Italian stock exchange using GARCH. Applied Financial Economics $12,183-192$.

Bunn, D., Fezzi, C., 2007. Interaction of European Carbon Trading and Energy Prices. Fondazione Eni Enrico Mattei Working Paper 123.

Chan, K., Chung, Y.P., Fong, W.-M., 2002. The informational role of stock and option volume. Review of Financial Studies 15, 1049-1075.

Chesney, M., Taschini, L., 2008. The endogenous price dynamics of the emission allowances: an application to $\mathrm{CO}_{2}$ option pricing. Swiss Finance Institute Research Paper Series, 08-02.

Chevallier, J., 2009. Carbon futures and macroeconomic risk factors: A view from the EU ETS. Energy Economics 31, 614-625.

Chevallier, J., Ielpo, F., Mercier, L., 2009. Risk aversion and institutional information disclosure on the European carbon market: a case-study of the 2006 compliance event. Energy Policy 37, 15-28.

Christiansen, A.C., Arvanitakis, A., Tangen, K., Hasselknippe, H., 2005. Price determinants in the EU emissions trading scheme. Climate Policy 5, 15-30.

Delarue, E.D., Ellerman, A.D., And D'haeseleer, W. 2008. Short-Term $\mathrm{CO}_{2}$ Abatement in the European Power Sector. $M I T$ CEEPR Working Paper 2008-008.

Ellerman, A.D., Buchner, B.K., 2008. Over-allocation or abatement? A preliminary analysis of the EU ETS based on the 2005-06 emissions data. Environmental and Resource Economics 41, 267-287.

Ellerman, A.D., And Feilhauer, S. 2008. A Top-down and Bottom-up Look at Emissions Abatement in Germany in Response to the EU ETS. MIT CEEPR Working Papier 2008-017.

Engle, R.F., Bollerslev, T., 1986. Modelling the persistence of conditional variances. Econometric Reviews 5, 1-50.

Fleming, J., Ostdiek, B., 1999. The impact of energy derivatives on the crude oil market. Energy Economics 21, 135-167.

Foster, D., Nelson, D., 1996. Continuous record asymptotics for rolling sample estimators. Econometrica 64, 139-174.

Geman, H., 2005. Commodity and Commodity Derivatives: Modeling and Pricing for Agriculturals, Metals and Energy. John Wiley and Sons, Ltd. Edition.

Gulen, H., Mayhew, S., 2000. Stock index futures trading And volatility in international equity markets. Journal of Futures Markets 20, 661-685. 
Hadsell, L., Shawky, H.A., 2006. Electricity price volatility and the marginal cost of congestion: an empirical study of peak hours on the NYISO market, 2001-2004. Energy Journal 27, 157-179.

InClán, C., TiaO, G., 1994. Use of cumulative sums of squares for retrospective detection of change of variance. Journal of the American Statistical Association 89, 913-923.

Kanen J.L.M., 2006. Carbon Trading and Pricing. Environmental Finance Publications.

Liu, C., Maheu, J.M., 2008. Are there structural breaks in realized volatility? Journal of Financial Econometrics 6, 326-360.

Mansanet-Bataller, M., Pardo, A., Valor, E., 2007. $\mathrm{CO}_{2}$ prices, energy and weather. Energy Journal 28, 73-92.

MaYhew, S., 2000. The impact of derivatives on cash markets: what have we learned? Unpublished manuscript, University of Georgia, February.

OBerndorfer, U., 2009. EU emission allowances and the stock market: evidence from the electricity industry. Ecological Economics 68, 1116-1126.

Paolella, M.S., Taschini, L., 2008. An econometric analysis of emission trading allowances. Journal of Banking and Finance 32, 2022-2032.

Rapach, D.E., Strauss, J.K., 2008. Structural breaks and GARCH models of exchange rate volatility. Journal of Applied Econometrics 23, 65-90.

Sansó A, ARragoó V, Carrion JL, 2004. Testing for change in the unconditional variance of financial time series. Revista de Economiá Financiera 4, 32-53.

Stranlund, J.K., Costello, C., Chávez, C.A., 2005. Enforcing emissions trading when emissions permits are bankable. Journal of Regulatory Economics 28, 181-204.

Uhrig-Homburg, M., Wagner, M., 2007. Derivative instruments in the EU emissions trading scheme - an early market perspective. Working Paper, Chair of Financial Engineering and Derivatives, Universitat Karlsruhe.

Weaver, R.D., Banerjee, A., 1990. Does Futures Trading Destabilize Cash Prices? Evidence for U.S. Live Beef Cattle. Journal of Futures Markets 10, 41-60. 